\title{
Transport Logistics Optimization Model Of Passenger Car Based On Heuristic Algorithm
}

\author{
Juan Zhou ${ }^{1,2}$, Mao Sheng Zhong ${ }^{3}$ Dao Lei Cheng ${ }^{1}$ and Xie Xin $^{3}$ \\ 1.School of Software \\ 2.Intelligent Optimization \& Information Processing Lab \\ 3.School of Information Engineering, East China Jiaotong University, Nanchang 330013
}

\begin{abstract}
Passenger car logistics transportation problem is at the primary stage of development in China, great economic loss and waste of resources caused in the process of logistics transportation,because most of enterprises in China rely on artificial experience for guidance at present.And use of a particular genetic algorithm to solve this problem by previous also exist many defects, such as programming complexity, instability and low efficiency etc.In view of this, The heuristic algorithm designing based on the greedy thought and the 0-1 knapsack thought was proposd, according build a universal model of the logistics transportation to the passenger car.Experimental results show, this model not only recording the concrete scheme of loading,also can make the optimization by changing the loading sequence.etc. This model is applicable to solve similar problems of transport logistics, and containing great practical application value and economic value.
\end{abstract}

Keywords Passenger car logistics transportation problem The greedy thought The 0-1 knapsack thought

\section{INSTRUCTIONS}

Passenger transport logistics problem refers to the production of passenger cars off the assembly line after finished, By means of transport, and distribution to all distribution warehouse, and finally to a series of storage and transportation process in the hands of consumers. How to use the limited means of transport, and to minimize the cost of [1] to be complete this process is a thorough study of the problems.At present, most of China's passenger car stowage scheduling logistics companies mainly rely on manual operation, depending on experience dispatchers, the prevalence of the following questions:1) lack of scientific methods to guide; 2) work-intensive, low efficiency; waste 3) car carriers capacity, high cost.For car carriers stowage plan and the lack of in-depth study of the lack of strong support software tools lead to the root cause of this problem.

Passenger transport logistics problems can be divided into loading problem and vehicle routing problem two sub-problems to solve.Loading Problem belong combination [2-3] Mathematics category, the paper loading problem based on rules that CLP (Container Loading Problems) issues.To solve this problem, heuristic algorithm foreign scholars have George \& Robinson (referred to as the G \& R) algorithm [4], Ngoi algorithm [5] and
Loh \& Nee algorithm [6].Domestic, He Dayong [7] Based on Space Decomposition layout heuristic genetic algorithm processing container loading problem;Wanch [8] proposed a hybrid genetic algorithm based on stereotypes and adaptive heuristic techniques to solve the actual operation of the most common weak heterogeneous container loading problem;Guo Hongwei [9] proposed the concept of "spatial layout point", and are using heuristic algorithms, genetic algorithms and simulated annealing algorithm. They common drawback of programming complexity, instability, and the solution process is slow.The difficulty of the problem is how to resolve the issue as one-dimensional multi-dimensional problem and how to solve the ultimate problem of sub-problems, which requires the use of dynamic programming.

This article based on ideology and greed 0-1 knapsack [10-12] dynamic programming ideas to construct heuristic algorithm to construct logistics model, and find the corresponding reprint and distribution programs to passenger transport and logistics issuesIt is converted to P class of problems, and accurately solved in polynomial time.The paper is arranged as follows: Section I introduces the background passenger transport and logistics problems, research status and the purpose and significance of the study; Section introducing practical problems to set forth the proposed 
modeling scheme; s three, elaborated on the establishment and solution models, and details the corresponding algorithm; the fourth quarter, this model is summarized.

\section{2 issues into}

Through modeling and solving a practical problem as an example,to elaborate modeling of the model solution process, the question summarized as follows: passenger car manufacturer according to the customer's purchase orders nationwide (Table 1):

Table1 list the distribution of passenger cars needs NOTE: A representation A land demand

\begin{tabular}{|c|c|c|c|c|c|c|c|c|c|}
\hline $\begin{array}{c}\mathrm{N} \\
0\end{array}$ & Brand & $\begin{array}{c}\text { Long } \\
(\mathrm{mm})\end{array}$ & $\begin{array}{c}\text { Width } \\
(\mathrm{mm})\end{array}$ & $\begin{array}{c}\text { High } \\
(\mathrm{mm})\end{array}$ & $\mathrm{A}$ & $\mathrm{B}$ & $\mathrm{C}$ & $\mathrm{D}$ & $\mathrm{E}$ \\
\hline 1 & Benz & 4610 & 1826 & 1763 & 4 & 2 & 0 & 3 & 1 \\
\hline 2 & Benz & 5015 & 1880 & 1475 & 2 & 3 & 0 & 4 & 2 \\
\hline 3 & Benz & 4310 & 1693 & 1480 & 12 & 6 & 5 & 10 & 7 \\
\hline 4 & modern & 4747 & 1820 & 1440 & 15 & 8 & 4 & 9 & 6 \\
\hline 5 & Honda & 3460 & 1618 & 1465 & 12 & 8 & 7 & 21 & 6 \\
\hline
\end{tabular}

Transportation logistics company issued to passenger cars to the task throughout the country, the logistics companies plan to develop transport and distribution in accordance with the mandate issued by these passenger cars. To this end, the logistics company first they were selected from a number of vehicle car carriers can call "car carriers" (Table 2 below):

Table 2 has a list of car carriers

\begin{tabular}{|c|c|c|c|c|c|}
\hline No. & type & $\begin{array}{c}\text { long } \\
(\mathrm{m})\end{array}$ & $\begin{array}{c}\text { Width } \\
(\mathrm{m})\end{array}$ & High (m) & $\begin{array}{c}\text { Owners } \\
\text { hip }\end{array}$ \\
\hline 1 & 1-1type & 19 & 2.7 & 4.35 & 21 \\
\hline 2 & $1-2$ type & 23.7 & 2.8 & 3.9 & 10 \\
\hline 3 & 2-2type & 19 & 3.5 & 3.4 & 5 \\
\hline
\end{tabular}

Which gives each passenger a car transport car loading programs and destinations, in order to ensure the completion of the transport task, the paper involved in car carriers in three models: the next upper each load a passenger, remember 1-1 type; in the upper load 1,2 respectively column, referred to as 1-2 type; in upper various load 2, recorded as 2-2.

Load requirements are as follows: Each car transport car, the lower the loading area can be considered equivalent to a rectangle, each longitudinal row of passenger cars were placed longitudinally and transversely between adjacent passenger cars are at least as safe distance between vehicles $0.1 \mathrm{~m}$, lower strive to fill the upper two symmetrical strive to ensure a smooth ride car carriers, the line shown in Figure 1.

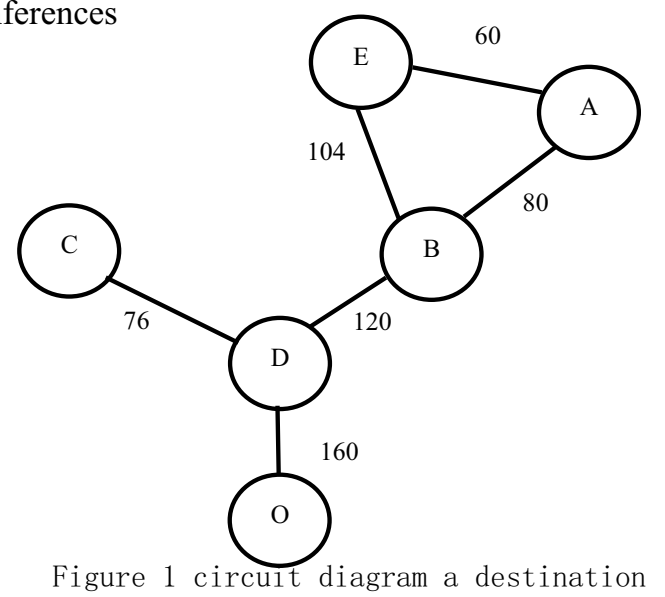

\section{Examples of Modeling}

Previous section details the problems to be solved, this section will establish the corresponding mathematical model of the problem.First, the modeling process need to make the following assumptions: (1) car carriers on standby after arrival, without emptying return; (2) the cost per Unloading almost negligible; and (3) that the cost per unit distance simplify and model-independent; (4) does not consider the special circumstances that occurred during the actual transport; (5) car carriers can not turn back.

\section{1 Model analysis}

This problem has several different types of car carriers and a number of different models of cars, and there is a triangular network path shown in Figure 1 [13]. Because of the limited number of car carriers, and therefore should be the first consideration is to be able to hold all the goods vehicles, followed by the total distance before considering the issue, the node $\mathrm{D}$ is a key node problem.In order to simplify the problem, trying to FIG divided into two lines, but because of too many models of goods vehicles and not be able to enumerate how to assign to two branch road, so it can be divided into two sub-path path directly to the point and the point together transport, after transport direction before going to demand, as shown in Figure 2.

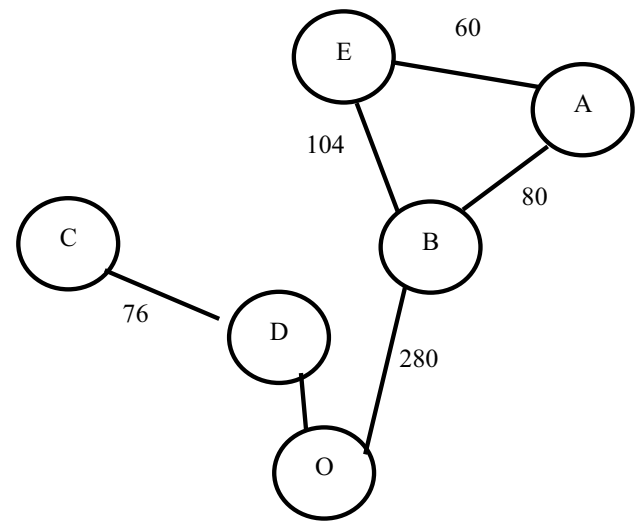

Figure 2 Figure II line destination

Then you can start with the first one first car carriers, according to the order for loading, and the first shipment of direction, until demand for 
passenger cars and a variety of point all 0 , and then further direction for shipment.During shipment, due to the size of the car models are different, so the vehicle when installed, should determine the size meets the requirements, and then decide to install or not install.After all the goods vehicles Bahrain, according to backpack load process the recorded program, the calculation of specific per car carriers actual distribution lines.First principle and point to stop at car carriers allocated, allocation: go after the order enumerate direction of the car, according to various distribution shipment demand for passenger cars, all to meet the farthest point, the remaining amount of car all will be docked at the $\mathrm{D}$ point.But there are some car though docked in point, but there is remove the part of the goods at the point, this may count for each item separately vehicles remaining amount, which in turn find the point after the previous, with the remaining amount of demand for this point subtraction, if they oversupply, will continue to find its former relay node.Since the backpack obtained during shipment program must be just to meet shipment demand, so eventually will find its most start unloading point.

Obtaining the specific distribution plan, we got the number in each node docked car carriers, then you can calculate the total distance of the program.

\subsection{Model establish}

Simplified diagram of the transport and two independent directions $O C$ and $O A$, the definition $y$ represents $O C$ the kind of $i$ demand for passenger cars, empathy $x$ is defined $O A$ demand for passenger cars, said first kind $i$, and $\operatorname{car}_{i}(n)$ is defined as a passenger $n$ point of the first species on the passenger the demand for the kind of $i$ car, thereby obtaining the following equation:

$$
\begin{aligned}
& y_{i}=\operatorname{car}_{i}(\mathrm{C})+\operatorname{car}_{i}(\mathrm{D}) \\
& x_{i}=\operatorname{car}_{i}(\mathrm{~A})+\operatorname{car}_{i}(\mathrm{~B})+\operatorname{car}_{i}(\mathrm{E})
\end{aligned}
$$

$O C$ hypothesis needs direction $k$ cars car carriers need to accomplish this $k$ cars car carriers may include three models, In order to meet the needs of its car carrier below filled with as much as possible, let's start from the lower load, in order to meet the requirements for the bottom of the two columns to symmetric, we try to fill up the columns, maximize space utilization. Therefore, the introduction of the 0-1 knapsack algorithm to solve this problem, and with the idea of dynamic programming to solve this problem. Definition methods: $\operatorname{solution}\left(s, T_{i}, l, w, h\right)$, That the use of a given car carriers loaded the remaining i-type passenger car program. Where $s$ is currently used model car carriers, $T_{i}$ represents the number of the remaining need to be loaded i-type ride transport vehicles, $l, w, h$ car carriers currently using the length and breadth. But this is only the loading program car carriers in a column position. So for the 1-1 type car carriers, adjustment shall be co-loaded sequence twice from bottom to top: $2 * \operatorname{solution}\left(s, T_{i}, l, w, h\right) ; 1-2$ basis having car from bottom to top, from left to right and then co-loaded three times: $3 * \operatorname{solution}\left(s, T_{i}, l, w, h\right) ; 2-2$ type car as from bottom to top, from left to right in all loading four times: $4 * \operatorname{solution}\left(s, T_{i}, l, w, h\right) . \mathrm{G}$ were used car transport car, you can get the following formula:

$$
\begin{aligned}
R= & \sum_{i=1}^{k} \operatorname{solution}\left(s, x_{i}, l, w, h\right) * t+ \\
& \sum_{j=k}^{g} \operatorname{solution}\left(s, y_{i}, l, w, h\right) * t, t \in\{2,3,4\}
\end{aligned}
$$

$\mathrm{T}$ from the value of the $\mathrm{s}$. As $\operatorname{solution}\left(s, T_{i}, l, w, h\right)$ is a single single loading problem, so the car transport the position the lower single aspect high value can be determined according to $l, w, h$. We will be the car car carrier single row as a container for $l$ long, with the given passenger car filled according to the specific space requirement.Let $d p(v)=1$ to $v$ represents the size of the space has been filled, to obtain the following formula:

$$
d p(v)=d p\left(v-v_{i}\right)>0 ? 1: 0
$$

If the size is expressed $v-v_{i}$ space has been filled, then the passenger $i$ load length of $v_{i}$, $v$ space size will also be filled Note that initially $d p(0)=1$.

In the calculation of the loading process, the need to record the specific circumstances of each of the next load.After that, according to the route problem solving concrete delivery vehicle specific programs, including the initial program loading, and unloading volume intermediate stops, as well as the final stops.Let number $\left(n_{i}\right)$ represents the final stop in $n_{i}$ number of car carriers, it can be calculated, the total number of miles traveled by car carriers to obtain the following formula:

$$
S=\sum_{i=A}^{D} \operatorname{dis}\left(n_{i}, O\right) * \text { number }\left(n_{i}\right)
$$

Where $S$ represents the total number of miles traveled, $\operatorname{dis}\left(n_{i}, O\right)$ represents the shortest 
distance $O$ of $n_{i}$. Requirements $\operatorname{dis}\left(n_{i}, O\right)$, according to the following formula (Floyd algorithm):

$$
\operatorname{dis}(i, j)=\operatorname{Min}(\operatorname{dis}(i, k)+\operatorname{dis}(k, j), \operatorname{dis}(i, j))
$$

\section{3 Algorithm Description}

Algor ithm 1 Loading process of the algorithm is described as follows:

1) The cumulative total for each model of each destination passenger demand $O C$ direction; 2) Enumeration of the i-th car carriers j-cars, its loading vehicles. According to the i-th model car carriers, the election of the corresponding load means (such as described in 3.2);

3 ) Enumerate each task is not yet complete loading of the passenger, assuming $k$ numbers $v_{k}$ passenger cars left, try to mount the first $i$ kind of car carriers $j$-cars. And record the loading programs;

4) Analyzing the i-th car carriers j-vehicle whether there is space, if there is, the implementation of $k=k+1$, skip to Procedure 3), and if not, skip to process 5);

5) Determine the direction of the loading task is completed, if not yet complete, execute $j=j+1$, if $j$ exceeds a given range, execution jumps to $i=i+1$, process 2) If you have completed skip to $6)$;

6) To determine whether there is a path did not complete loading, if there is, skip to procedure 7), otherwise skip to process 8);

7) Accumulated $\mathrm{OA}$ direction of each destination the total demand for passenger cars for each model, the Executive $j=j+1$, if $j$ exceeds a given range, execution $i=i+1$, skip to Procedure 2);

8) The loading program records, calculates per car carriers transport path and calculate the final number of car carriers docked at each destination, the statistical total distance.

Algorithm 2 According stowage plans, calculate specific delivery routes algorithm is described as follows:

1) per enumeration packed car carriers, starting from the current path farthest destination stowage, provided the current destination node;

2) $i$ enumerate car carriers loaded passenger $j$, set up a total of $v_{j}$ vehicles;

3) Analyzing the current $v_{j}$ passenger cars exceeds $n$-point demand for $\mathrm{j}$ passenger cars, if not exceed, home need $[n] . \operatorname{car}[j]=0$, execute $j=j+1$, skip to Procedure 2); otherwise, the process jumps to 4$)$;

4) n calculated point before a node $\operatorname{pre}[n]$, update

$$
v_{j}=v_{j}-\text { need }[n] . \operatorname{car}[j]
$$

which need $[n] . \operatorname{car}[j]$ represents node of $\mathrm{n}$ demand for passenger car j,put need $[n] . \operatorname{car}[j]=0$;

5) Print out the distribution record $n$ nodes, and set $n=\operatorname{pre}[n]$, such as $n=\operatorname{pre}[n]$ does not exist, skip to procedure 7);

6) Analyzing $v_{j}$ is 0 , and if yes, then execute $j=j+1$, the process jumps to 10 ); if not, skip to Procedure 4);

7) Determine whether there are car carriers useless statistics, if there is, do $i=i+1$, skip process 2), otherwise the algorithm ends.

\section{4 model solution}

According to the above models and algorithms

\begin{tabular}{|c|c|c|c|c|c|c|}
\hline Vehicle order & Car name & models & Car layer & $\begin{array}{l}\text { Loading mode }(\mathrm{a}, \mathrm{b}) \\
\mathrm{A} \text { passenger car } \\
\text { number } \mathrm{b}\end{array}$ & $\begin{array}{l}\text { Unlouading capacity in middle point } \\
(\mathrm{X}, \mathrm{Y}, \mathrm{Z}) \text { which unlouding } \mathrm{Z} \\
\text { vehiccles of } \mathrm{Y} \text { types in place } \mathrm{X}\end{array}$ & termini \\
\hline \multirow[t]{2}{*}{1} & 1 & $1-1$ & Upper layer & $(3,2),(5,3)$ & & $\mathrm{C}$ \\
\hline & & & Lower & $(3,2),(5,3)$ & & \\
\hline \multirow[t]{2}{*}{2} & 1 & $1-1$ & Upper layer & $(3,2) 、(5,3)$ & $(\mathrm{D}, 3,3),(\mathrm{D}, 5,5)$ & $\mathrm{C}$ \\
\hline & & & Lower & $(3,2),(5,3)$ & & \\
\hline \multirow[t]{2}{*}{3} & 1 & $1-1$ & Upper layer & $(3,2) 、(5,3)$ & $(\mathrm{D}, 3,4),(\mathrm{D}, 5,6)$ & $\mathrm{D}$ \\
\hline & & & Lower & $(3,2) 、(5,3)$ & & \\
\hline \multirow[t]{2}{*}{4} & 1 & $1-1$ & Upper layer & $(4,4)$ & $(\mathrm{D}, 3,2),(\mathrm{D}, 5,3)$ & $\mathrm{C}$ \\
\hline & & & Lower & $(3,2),(5,3)$ & & \\
\hline
\end{tabular}
to obtain results as shown in Table 3: 


\begin{tabular}{|c|c|c|c|c|c|c|}
\hline 5 & 1 & $1-1$ & Upper layer & $(4,4)$ & & $\mathrm{D}$ \\
\hline & & & Lower & $(4,4)$ & & \\
\hline 6 & & & Lower & $(1,2) 、(2,1) 、(4,1)$ & & \\
\hline 7 & & & Lower & $(2,1) 、(5,4)$ & & \\
\hline \multirow[t]{2}{*}{8} & 1 & $1-1$ & Upper layer & $(3,2) 、(5,3)$ & & $\mathrm{E}$ \\
\hline & & & Lower & $(3,2),(5,3)$ & & \\
\hline 9 & 1 & $1-1$ & Upper layer & $(3,2) 、(5,3)$ & $(\mathrm{A}, 3,1),(\mathrm{A}, 5,6)$ & $\mathrm{E}$ \\
\hline 10 & & & Lower & $(3,2) 、(5,3)$ & & \\
\hline \multirow[t]{2}{*}{11} & 1 & $1-1$ & Upper layer & $(3,2),(5,3)$ & $(\mathrm{A}, 3,4),(\mathrm{B}, 5,6)$ & A \\
\hline & & & Lower & $(3,2) 、(5,3)$ & & \\
\hline \multirow[t]{2}{*}{12} & 1 & $1-1$ & Upper layer & $(4,4)$ & $(\mathrm{A}, 4,2)$ & $\mathrm{E}$ \\
\hline & & & Lower & $(4,4)$ & & \\
\hline 13 & 1 & $1-1$ & Upper layer & $(4,4)$ & $(\mathrm{A}, 4,8)$ & A \\
\hline \multirow[t]{2}{*}{16} & 1 & $1-1$ & Upper layer & $(1,1) 、(2,2) 、(3,1)$ & $(\mathrm{A}, 1,2) 、(\mathrm{~A}, 2,2) 、(\mathrm{~A}, 3,2) 、(\mathrm{~B}, 2,1)$ & $\mathrm{E}$ \\
\hline & & & Lower & $(1,1) 、(2,2) 、(3,1)$ & & \\
\hline \multirow[t]{2}{*}{17} & 1 & $1-1$ & Upper layer & $(1,2) 、 \quad(3,2)$ & $(\mathrm{B}, 1,2) 、(\mathrm{~B}, 2,2) 、(\mathrm{~B}, 3,2)$ & A \\
\hline & & & Lower & $(1,1) 、(2,2) 、(3,1)$ & & \\
\hline \multirow[t]{2}{*}{18} & 1 & $1-1$ & Upper layer & $(5,2)$ & & $\mathrm{B}$ \\
\hline & & & Lower & $(3,4)$ & & \\
\hline \multicolumn{4}{|c|}{ Total distance } & \multicolumn{3}{|c|}{5520} \\
\hline
\end{tabular}

By adjusting the car carriers loading order, you can get a different load transport programs, the following comparison between different options of its exemplar 4 is as follows:

Table 4 car carriers adjustment sequence loading program obtained Compare

\begin{tabular}{|c|c|c|c|}
\hline Program & Sequence & $\begin{array}{c}\text { Number of car } \\
\text { carriers }\end{array}$ & $\begin{array}{c}\text { Total } \\
\text { distance }\end{array}$ \\
\hline 1 & 123 & 18 & 5520 \\
\hline 2 & 132 & 18 & 5520 \\
\hline 3 & 213 & 20 & 5940 \\
\hline 4 & 231 & 19 & 5660 \\
\hline 5 & 312 & 15 & 4668 \\
\hline 6 & 321 & 15 & 4668 \\
\hline
\end{tabular}

Through Table 4 we found that the program loading sequence 5 and 6 can be used to make car carriers number and total distance are relatively small. Thus show that the model can adjust the load order to achieve the effect of optimization models.

\section{Conclusion}

The time complexity of the model analysis as follows: Suppose a total of $M$ cars need to use car carriers and distribution $N$ cars, car carriers which length is $L$, then every - time during loading time complexity is $O(N L)$, Assuming a positive integer $2 \leq k \leq 4$, the complexity of the whole loading process there is $o\left(\sum_{i=1}^{M N L}\right)$. A number $n$ for the middle of the unloading point, and then calculate its car carrier consumed by a specific distribution path time complexity is $O(n M)$. Let the path a total of $Z$ sites, if $Z \leq 100$,Algorithm Floyd [14] to solve the shortest path between points, time 
complexity $O\left(Z^{3}\right)$; If Z, algorithm SPFA [15-16] Solving the shortest time complexity is $\mathrm{O}(\mathrm{ZE})$, where $E$ is the figure of the total number of edges, So the algorithm's time complexity is $O\left(\sum^{M} k N L\right)+O(n M)+\min \left(O\left(Z^{3}\right), O(Z E)\right) \quad$, the model is suitable for large-scale car car carrier load distribution scheme.

The proposed model can be solved to a certain extent in our asked the passenger vehicle logistics transportation problem today. In the future work, will do the further research on the model, the improvement and optimization, and the corresponding software system, and its promotion to the commercial market.

\section{Acknowledgments}

This work was supported by the National Natural Science Fund of China (No.61462027, No. 61163055, No. 61165004), and by science\& technology pillar program of Jiangxi province (20151BBE50055), and by Science Fund of ECJT University(No.13RJ04).

\section{References}

[1] Li Da,Capital University of Economics and Business,Beijing,2012.

[2] Zhang Jiangjin, Combinatorial Packing Problem: Models and Algorithms[D].Shanghai Jiao Tong University,2012.

[3] ZHANG Jiangjing,CHEN Feng.One-dimensional Packing Problem with Loading Combination Contraints.Industrial Engineering and Management.2012,17(3):90-96.

[4] Eberhard E.Bischoff ,Michael D.Marriott.A comparative evaluation of heuristics for container loading[J].European Journal of Operational Research 1990,44(2):267-27.

[5] B.K.A.Ngoi, M.L.Tay, E.S.Chua.Applying spatial representation techniques to the container packing problem[J].International Journal of Production Research,1994,32(1): 111-123.

[6] T. H. Loh, A. Y. C. Nee.A packing algorithm for hexahedral boxes[C].In:Proceedings of the Conference of Industrial Automation, Singapore ,February 1992: $115-126$

[7] HE Dayong,E Mingcheng,CHA Jianzhong,WANG Chun Xi,JIANG Yi Dong.A Heuristic Approach to Container Loading Problem Based on Space
Decomposition and A Rule for Usage Rate of Packing Space, Journal of Computer-Aided Design \& Computer Graphics. 2000,12 (5) :367-370.

[8] Huang Chuan.The Research of the Optimization Algorithm of the Container Loading Problem.Fujian Normal University 2005.

[9] Guo Hongwei, Development of airborne packing scheme and software development of the logistics system.qingdao,qingdao University, 2005.

[10] Shan Xiaojun ,Wu Suping. Solving 0-1 Knapsack Problems with Genetic Algorithm Based on Greedy Strategy,Computer Applications and Software,2010,27(12):238-240.

[11] SHI Lan,LV Jian-hui.New optimization algorithm of 0-1 knapsack problem.Application Research of Computers,2014,31(4):997-1000.

[12] YU Juan,HE Yuyao. Hybrid algorithm based on Genetic Algorithm and estimation of distribution algorithm for 0-1 knapsack problem. Computer Engineering and Applications, 2014,50 (9) :12-16.

[13] SONG Wenfeng.The Research of Finished Vehicle Logistics Based on Tirangle Distribution Network[D].Hefei University of Technology,2012.

[14] WANG Hua,A mixed algorithm of shortest path in logistics and distribution. Science of Surveying and Mapping, 2014.39 (9) : 135-137.

[15] SHEN Hai-lan,WANG Yu-bin,CHEN Zai-liang,CA,Zi-wen Improved SPFA Algorithm Based on Layered Graph,Computer Engineering, 2012,38 (13):251-253.

[16] WU Xiao-zhen,LI Biao-kui,DONG Zi-yan,LI Bo-xing ZHAN Jun The Optimization and Solving of Vehicle Logistics Transport Routes and the Mode of Transportation Based on SPFA. Logistics Engineering and Management, 2014,36 (5):176-178.

Zhou Juan is a full lecture of School of Software at East China Jiaotong University, female,born on September, 1977.She is the instructor of the Mathematical Contest in Modeling and the coach of ACM ICPC(International Collegiate Programming Contest).Her current research interests include design and analysis of computer algorithms and Graph Theory. 